\title{
Estimation of genetic parameters and heterosis for longevity in crossbred Danish dairy cattle
}

\author{
J. B. Clasen, ${ }^{*} \dagger^{1}$ E. Norberg, ${ }^{*}$ P. Madsen, ${ }^{*}$ J. Pedersen, $\dagger$ and M. Kargo ${ }^{*} \dagger$ \\ *Department of Molecular Biology and Genetics, Science and Technology, Aarhus University, 20 Blichers Allé, 8830 Tjele, Denmark \\ †SEGES, 15 Agro Food Park, 8200 Aarhus N, Denmark
}

\begin{abstract}
Crossbreeding has been shown to improve the longevity of dairy cattle in countries across the world. The aim of this study was to estimate heterosis, breed effects, and genetic parameters for longevity in crossbred dairy cattle among Danish Holstein (DH), Danish Red (DR), and Danish Jersey (DJ) breeds. Data were provided from 119 Danish commercial herds that use systematic crossbreeding (i.e., rotational crossbreeding). Additional data from 11 mixed-breed herds with $\mathrm{DH}$ and DJ were included to estimate reliable breed effects for DJ. Survival information on 73,741 cows was analyzed with a linear animal model using the artificial insemination-REML algorithm in the DMU package. Five longevity (L) traits were defined: days from first calving until the end of first lactation or culling (L1), days from first calving until the end of second lactation or culling (L2), days from first calving until the end of third lactation or culling (L3), days from first calving until the end of fourth lactation or culling (L4), and days from first calving until the end of fifth lactation or culling (L5). Heritabilities ranged between 0.022 and 0.090 . Additive breed effects in units of days were estimated relative to $\mathrm{DH}$ for $\mathrm{DR}$ as -0.5 (L1), +10.5 (L2), +18.5 (L3), +11.9 (L4), and +28.6 (L5), and corresponding figures for DJ were $+2.0,+0.5,+14.2,+27.7$, and +44.0. Heterosis effects in L1 were low $(1.2 \%)$ but favorable in crosses between $\mathrm{DH}$ and $\mathrm{DR}$, whereas negative heterosis effects were estimated for crosses between DH and DJ $(-2.5 \%)$ and DR and DJ $(-1.2 \%)$. The largest heterosis effects for L2, L3, L4, and L5 were found in $\mathrm{DH} \times \mathrm{DR}$ and were favorable $(+3.3,+5.7$, +7.7 , and $+8.5 \%$, respectively). Corresponding figures for heterosis effects in $\mathrm{DH} \times \mathrm{DJ}$ and $\mathrm{DR} \times \mathrm{DJ}$ were favorable as well: $+2.3,+4.1,+5.6$, and $+6.2 \%$ in $\mathrm{DH}$ $\times$ DJ and $+3.1,+7.3,+6.9$, and $+7.2 \%$ in DR $\times$ DJ.
\end{abstract}

\footnotetext{
Received January 23, 2017.

Accepted April 2, 2017.

${ }^{1}$ Corresponding author: julieclasen@mbg.au.dk
}

The favorable heterosis effects show that crossbreeding is an efficient tool for improving longevity in Danish dairy cattle.

Key words: dairy cattle, crossbreeding, longevity

\section{INTRODUCTION}

During the last decades, the focus on including longevity and functional traits (mainly fertility, health, and conformation) in dairy cattle breeding goals has increased throughout the world (Leitch, 1994; Miglior et al., 2005; Kargo et al., 2014). Longevity is a complex trait that is highly affected by production and functional traits as well as other factors such as herd management and the farmer's decisions (Berry et al., 2005). In Denmark, the average lifetime of dairy cows is approximately 2.5 lactations (SEGES, 2015). Yet studies indicate that the full milk yield potential of a cow is not obtained until the third or fourth lactation (Jairath et al., 1998), assuming that this is when the cow may become most profitable. However, as the cow gets older, the functional traits may deteriorate (Fleischer et al., 2001; Weber et al., 2013), and in many cases the cow will therefore be culled before it reaches its full milk yield potential.

Herd management is a key factor in minimizing the decline in functional traits and improving longevity (de Mello et al., 2014), but longevity is also influenced by genetics. Heritability estimates for longevity are highly dependent on how it is analyzed; reported estimates range from 0.03 to 0.39 (Roxström and Strandberg, 2002; SEGES, 2015). The complexity of longevity makes it hard to define a measurable phenotype and select directly for longevity. However, large genetic correlations between production, functional traits, and longevity exist (Roxström and Strandberg, 2002; Pritchard et al., 2013). This suggests that selection can be based on production and functional traits rather than directly on longevity. Indeed, this is accounted for in the Nordic Total Merit Index, where the largest weights are put on milk yield, udder health, and udder conformation (NAV, 2013). 
Crossbreeding between purebred lines or populations is known to produce offspring with better economic and phenotypic abilities compared with the parental breeds. Systematic crossbreeding (i.e., rotational crossbreeding) has been used successfully within beef cattle, poultry, and pig production systems for a long time but is less common in dairy cattle. However, interest in systematic crossbreeding has been increasing throughout the world during the last decade (Sørensen et al., 2008). An experiment conducted in Denmark in the 1980s showed that longevity can be improved in Danish dairy cattle by using a crossbreeding scheme (Sørensen et al., 2008). Additionally, other studies such as those in Sweden (Jönsson, 2015), Canada (Vesely et al., 1986), the United States (Heins et al., 2011, 2012), and New Zealand (Lopez-Villalobos et al., 2000) have found improvement in longevity by crossbreeding. The use of systematic crossbreeding in Danish dairy herds is of increasing interest, and reliable estimates of the effect of crossbreeding under Danish circumstances will be of great value for both breeding organizations and dairy farmers. The aim of this study was to estimate heterosis, breed effects, and genetic parameters for longevity in crossbred dairy cattle among Danish Holstein (DH), Danish Red (DR), and Danish Jersey (DJ) breeds.

\section{MATERIALS AND METHODS}

\section{Data}

Data and information on survival, breed proportion, and relationships between animals were provided by the Danish Cattle Registry (SEGES) on 73,741 animals with a total of 188,678 calvings from November 10, 1999, to October 1, 2016. All animals had at least the first calving registered within that period. Data were extracted from 119 Danish commercial herds that use systematic crossbreeding and 11 mixed-breed herds with purebred DH and DJ. The herds using crossbreeding were selected by Danish breeding consultants. The mixed-breed herds were included to estimate breed effects between DJ and the other breeds, as the number of pure DJ represented in the herds using systematic crossbreeding was limited. The pedigree was traced back 4 generations and included 262,027 animals.

The data set exclusively contained data that met the following requirements: (1) the individual cow had a minimum age of $450 \mathrm{~d}$ and a maximum age of 1,280 d at first calving, (2) cows did not change herds during the observation period, and (3) unknown breed proportions did not exceed $12.5 \%$. Registration of breed proportion was not a standard procedure in Denmark until the late 1990s; thus, some cows may have proportions of unknown breed. Instead of removal, for the 2,994 cows with less than $12.5 \%$ unknown breed, the unknown proportion was substituted with the breed (DH, DR, or DJ) representing the largest proportion. This was done to keep as many crossbred animals in the data as possible.

It is important to note that the breeds $\mathrm{DH}, \mathrm{DR}$, and DJ contain more lines. Danish Holstein consists mainly of Holstein-Friesian, but it also contains a small proportion of Original Danish Black and White. Danish Jersey is a mixture of Danish, New Zealand, and American Jersey. Danish Red is the most heterogeneous breed because it contains a small proportion of Original Danish Red, whereas the remaining part is a mixture of Swedish Red, Norwegian Red, Canadian Ayrshire, Finnish Ayrshire, American Brown Swiss, and Red Holstein Friesian (SEGES, 2015). For our analysis, we wanted to keep the 3 breeds as distinct as possible. We therefore chose to include Red Holstein Friesian in DH instead of DR, as Red Holstein Friesian is more genetically related to $\mathrm{DH}$ than $\mathrm{DR}$.

\section{Longevity Traits}

Five longevity traits were constructed to reflect productive longevity, which is described as the number of days survived from first calving until culling, without correction for any production or functional traits. These 5 traits correspond to the traits used for evaluating longevity in the Nordic Cattle Genetic Evaluation (NAV; NAV, 2013). The longevity (L) traits are defined as follows: days from first calving until the end of first lactation or culling (L1), days from first calving until the end of second lactation or culling (L2), days from first calving until the end of third lactation or culling (L3), days from first calving until the end of fourth lactation or culling (L4), and days from first calving until the end of fifth lactation or culling (L5). A specific trait is the sum of days in all previous lactations plus the number of days until culling in the current lactation. Thus, an observation on L5 can be considered as the total longevity. To avoid penalizing particularly fertile cows, the number of days in lactation was set to 365 $\mathrm{d}$ if the cow was culled in a later lactation. Hence, the maximum observation was 365, 730, 1,095, 1,460, and 1,825 for L1, L2, L3, L4, and L5, respectively. However, in the lactation in which the cow was culled, the observation was set to the exact number of productive days (although a maximum of $365 \mathrm{~d}$ ). Furthermore, no censored data were included; thus, all cows with data had finished or had the opportunity to finish the current lactation number. 
Table 1. Least squares means (days) of observations (SE in subscript, no. of cows in parentheses) for 5 longevity (L) traits and mean breed percentage in crossbreds

\begin{tabular}{|c|c|c|c|c|}
\hline \multirow[b]{2}{*}{ Trait $^{1}$} & \multicolumn{4}{|c|}{ Breed $^{2}$} \\
\hline & DR & $\mathrm{DH}$ & DJ & Crossbred \\
\hline$\overline{\mathrm{L} 1}$ & $338_{1.6(3,166)}$ & $343_{1.1(32,437)}$ & $346_{1.8(2,738)}$ & $343_{1.1(29,478)}$ \\
\hline L2 & $546_{5.4(2,939)}$ & $558 \quad 3.6(29,796)$ & $5586.4(2,468)$ & $565_{3.8(25,294)}^{1 .(2,70)}$ \\
\hline L3 & $6689.2(2,730)$ & $6796.2(27,372)$ & $69011.2(2,201)$ & $693 \quad 6.5(21,202)$ \\
\hline L4 & $737_{12.3(2,482)}$ & $7428.0(24,742)$ & $76415.1(1,912)$ & $768_{8.5}(17,479)$ \\
\hline L5 & $765 \quad 14.6(2,266)$ & $7659.4(22,002)$ & $80018.4(1,641)$ & 799 10.3 (13,874) \\
\hline Mean breed \% in crossbreds & 33.5 & $56.3^{-42,002)}$ & $10.2^{10.4(1,041)}$ & - \\
\hline
\end{tabular}

\section{Model}

Table 1 shows the least squares means observations adjusted for herd $\times$ year of first calving, age at first calving, and month at first calving for the 5 traits in each breed group (DR, DH, DJ, and crossbred). Almost 10 times more DH and crossbreds contributed to the data compared with DR and DJ, which makes the standard errors for the 2 latter breed groups almost twice as large as those for the 2 former breed groups. Furthermore, the table shows the mean breed proportions in the crossbreds. The crossbreds contained, on average, $56.3 \%$ DH, $33.5 \%$ DR, and only $10.2 \%$ DJ.

For each trait, data were analyzed with a linear animal model using the AI-REML algorithm in the DMU package (Madsen and Jensen, 2013). Breed effects and heterosis effects were estimated, as was heritability as a function of the estimated variance components: additive genetic, residual, and phenotypic standard deviation. The model we used was constructed on the basis of the NAV longevity model (NAV, 2013):

$$
\begin{aligned}
\mathrm{Y}_{i j k l}=\mathrm{H}_{i} & +\mathrm{C}_{j}+\mathrm{M}_{k}+b_{\mathrm{DH}} \times p_{\mathrm{DH}}+b_{\mathrm{DR}} \times p_{\mathrm{DR}}+b_{\mathrm{DJ}} \\
\times p_{\mathrm{DJ}} & +b_{\mathrm{DH} \mid \mathrm{DR}} \times h e t_{\mathrm{DH} \mid \mathrm{DR}}+b_{\mathrm{DH} \mid \mathrm{DJ}} \times h e t_{\mathrm{DH} \mid \mathrm{DJ}} \\
& +b_{\mathrm{DR} \mid \mathrm{DJ}} \times h e t_{\mathrm{DR} \mid \mathrm{DJ}}+a_{l}+e_{i j k k}
\end{aligned}
$$

where $\mathrm{Y}_{i j k l}=$ record on an individual trait (L1, L2, L3, L4, or L5), $\mathrm{H}_{i}=$ fixed effect of herd $\times$ year of first calving $i, \mathrm{C}_{j}=$ fixed effect of age at first calving $j, \mathrm{M}_{k}$ $=$ fixed effect of calving month at first calving $k, b_{\mathrm{DH}} \times$ $p_{\mathrm{DH}}=$ regression on the proportion of $\mathrm{DH}$ genes, $b_{\mathrm{DR}} \times$ $p_{\mathrm{DR}}=$ regression on the proportion of DR genes, $b_{\mathrm{DJ}} \times$ $p_{\mathrm{DJ}}=$ regression on the proportion of DJ genes, $b_{\mathrm{DH} \mid \mathrm{DR}}$ $\times$ het $_{\mathrm{DH} \mid \mathrm{DR}}=$ regression on the degree of heterozygosity between $\mathrm{DH}$ and $\mathrm{DJ}, b_{\mathrm{DH} \mid \mathrm{DJ}} \times$ het $_{\mathrm{DH} \mid \mathrm{DJ}}=$ regression on the degree of heterozygosity between $\mathrm{DH}$ and DR, $b_{\mathrm{DR} \mid \mathrm{DJ}} \times$ het $_{\mathrm{DR} \mid \mathrm{DJ}}=$ regression on the degree of heterozygosity between DR and DJ, $a_{l}=$ additive genetic effect of cow $l$, and $e_{i j k l}=$ random residual.
Heterosis was estimated using a dominance model. The dominance effects were modeled as a regression on the degree of heterozygosity between DH and DJ, DH and DR, and DR and DJ. The degree of breed heterozygosity was estimated as dominance effects by the following equation:

$$
b \times h e t=P s_{i} \times P d_{j}+P s_{j} \times P d_{i},
$$

where $P s$ and $P d$ denote the proportion of breed $i$ and $j$ for the sire and dam, respectively.

\section{RESULTS AND DISCUSSION}

\section{Genetic and Phenotypic Parameters}

Genetic and phenotypic parameters for the 5 longevity traits are presented in Table 2 . Heritabilities ranged between 0.022 and 0.090 . The low heritability estimates are a result of small genetic variations and relatively large residual variations, which may be explained by the complexity of the traits and the large effect of management. The farmer's opinion has a large effect on the survival of the cow (Berry et al., 2005), as it is the farmer who makes the decision of whether a cow should be culled. A part of the farmer's opinion may be accounted for in our model by the fixed effect of herd $\times$ year at first calving because the farmer may be systematic in their decision. Other factors that may be included in the residual variation could be involuntary culling due to accidents on farm or culling to make room for new heifers. Also, the former milk quota system in the European Union, which was terminated in April 2015, may have led to early culling.

The low heritabilities for longevity found in our study agree well with what has been found in previous studies. Jairath et al. (1998) estimated the heritability to be 0.08 for longevity, defined as the number of lactations survived from 1 to 10 lactations based on ap- 
proximately 2.3 million Canadian Holstein cows. They also estimated a heritability of 0.03 for survival after 1,2 , and 3 lactations. This agrees well with estimates from Denmark (SEGES, 2015) from the NAV longevity evaluation of DH, DJ, and DR (as in this study). The heritabilities in the Danish report are very similar to our findings for the first 3 lactations (0.029-0.062) but somewhat smaller for L4 (0.063-0.069) and L5 (0.0640.072 ). In contrast to our study, the NAV genetic evaluation analyzes the individual breeds separately.

Larger heritabilities have been found by Roxström and Strandberg (2002), who used a survival analysis for production-determined, mastitis-determined, and fertility-determined longevity. The estimated heritabilities were $0.39,0.29$, and 0.16 for the 3 traits, respectively. In comparison, they estimated heritability of 0.10 for longevity with no trait determination. This supports the idea that production and functional traits have a large influence on longevity. However, traitspecific longevity may be considered as a different trait than longevity determined as productive life. Survival models can be considered more suitable because censored data are included compared with linear models. Adversely, they are more computationally demanding (NAV, 2013). Linear models for genetic evaluations are used in the countries participating in NAV (Denmark, Sweden, and Finland); therefore, we chose to use the same model for our study.

The additive genetic standard variations for the longevity traits presented in Table 2 increase from L1 through L5. Most cows survive their first lactation; therefore, most cows are assigned the maximum limit, which is $365 \mathrm{~d}$ for L1. This creates an abnormal distribution of the observations for the trait, causing the model to create an artificially small genetic variation. As the distribution of observations becomes more normal in later lactations, the variation increases as well. Thus, the genetic variations in Table 2 show that genetic progress is possible for the traits. Biologically, a larger genetic variation for L5 compared with L1 is expected because survival in later lactations provides

Table 2. Heritabilities $\left(\mathrm{h}^{2}\right.$; SE in parentheses) and additive genetic $\left(\sigma_{\mathrm{A}}\right)$, phenotypic $\left(\sigma_{\mathrm{P}}\right)$, and residual $\left(\sigma_{\mathrm{E}}\right)$ standard deviations for 5 longevity $(\mathrm{L})$ traits

\begin{tabular}{lcrrr}
\hline Trait $^{1}$ & $\mathrm{~h}^{2}$ & \multicolumn{1}{c}{$\sigma_{\mathrm{A}}$} & \multicolumn{1}{c}{$\sigma_{\mathrm{P}}$} & \multicolumn{1}{c}{$\sigma_{\mathrm{E}}$} \\
\hline L1 & $0.022(0.004)$ & 8.4 & 56.6 & 55.9 \\
L2 & $0.046(0.006)$ & 40.4 & 188.9 & 184.6 \\
L3 & $0.071(0.008)$ & 83.8 & 314.9 & 303.5 \\
L4 & $0.088(0.009)$ & 119.8 & 404.7 & 386.5 \\
L5 & $0.090(0.010)$ & 136.8 & 455.9 & 434.9 \\
\hline
\end{tabular}

${ }^{1} \mathrm{~L} 1=$ days from first calving until culling; L2 = days from second calving until culling; L3 = days from third calving until culling; L4 = days from fourth calving until culling; L5 = days from fifth calving until culling. more information on true longevity. In other words, a cow that survives many lactations has avoided culling because it has shown better fitness traits than the average cow.

\section{Breed Effects}

The additive breed effects of DR and DJ for L1 to L5 relative to $\mathrm{DH}$ are shown in Table 3 , but none of them are significant. However, the numbers may imply better breed effects of both DR and DJ compared with DH. For the first 3 lactations, DR seems slightly better than or at least equal to DJ, but for L4 and L5, DJ seems to be the superior breed. According to the statistics of Danish dairy cattle breeding from 1990 to 2014, DJ has always been superior in terms of longevity. However, the length of productive life has also decreased for DJ in that period. In contrast, longevity in DH has improved during the same period and almost reached the level of DJ in 2014. The level of longevity for DR is below that of the other breeds and has shown a declining tendency since 2010 (SEGES, 2015).

Functional traits have been a large focus in DR for many years; therefore, DR has shown better abilities for reproduction and health compared with the other breeds (Norberg et al., 2009). This is also reflected in the weights of the traits in the Nordic Total Merit Index for DR, where the weights on most functional traits are relatively low compared with DH and DJ because of the better performance of DR in these traits (NAV, 2013). In addition, the average replacement rate in DR has been rather high since 2009 (40-45\%; Lauritsen and Flagstad, 2016). This suggests that many well-functioning cows have been culled prematurely and replaced with heifers, and therefore the average age has decreased substantially. Thus, the breed effects show the true longevity abilities in DR, in contrast to the Danish statistics (SEGES, 2015). However, we did not find any explanation of why the breed effect for L4 for DR is lower than that for L3 when the opposite is to be expected.

Table 3. Additive breed effects (SE in parentheses) of Danish Red (DR) and Danish Jersey (DJ) relative to Danish Holstein on 5 longevity $(\mathrm{L})$ traits

\begin{tabular}{lcc}
\hline Trait $^{1}$ & DR & DJ \\
\hline L1 & $-0.5(3.0)$ & $+2.0(3.5)$ \\
L2 & $+10.5(12.4)$ & $+0.5(14.7)$ \\
L3 & $+18.5(23.7)$ & $+14.2(28.5)$ \\
L4 & $+11.9(33.4)$ & $+27.7(40.0)$ \\
L5 & $+28.6(39.5)$ & $+44.0(46.5)$ \\
\hline
\end{tabular}

${ }^{1} \mathrm{~L} 1=$ days from first calving until culling; L2 = days from second calving until culling; L3 = days from third calving until culling; L4 = days from fourth calving until culling; L5 = days from fifth calving until culling. 
In a study by Bijma et al. (1998) on Danish dairy cattle, there is agreement that DJ is the most durable breed and that DR is the least durable. The unadjusted means showed that DJ had 86 more DIM than DH, whereas DR had $18 \mathrm{~d}$ less. However, longevity for DJ after $15 \mathrm{mo}$ in lactation was equal to $\mathrm{DH}$ and $\mathrm{DR}$, but DJ became superior after 25 and 50 mo in lactation. Norberg et al. (2009) showed that DJ had more incidences of udder diseases in first lactation compared with the other breeds but less in later lactations. This is consistent with our estimates of breed effects and least squares means, which showed that DJ is superior in later lactations.

\section{Heterosis}

Heterosis estimates are presented in Table 4 in both percentage and days from the average of the parental breeds. Breed combinations are presented for all sire and dam combinations. All traits show significant heterosis between breed combinations. Heterosis estimates in crossbreds containing DJ are negative for L1, whereas other combinations show positive heterosis estimates for all traits. As previously explained, an abnormal distribution of observations for L1 is created because many cows are assigned the maximum limit of $365 \mathrm{~d}$. This gives limited heterosis because the parental averages are very close to $365 \mathrm{~d}$. Therefore, the negative heterosis estimates in L1 are mainly an artifact of the distribution of records and are not considered reliable. When fewer cows proceed into further lactations, the deviation from the parental averages to the maximum observation becomes larger. This makes the observations for L2, L3, L4, and L5 more normally distributed, which results in larger and more reliable heterosis estimates.

Only a few studies on crossbreeding and longevity are comparable with our study, and only one includes the Jersey breed. In an analysis by simulation of crossbreed- ing in dairy herds in New Zealand, Lopez-Villalobos et al. (2000) estimated heterosis effects of survival as +2.9 , +4.9 , and $+4.7 \%$ for Holstein $\times$ Ayrshire, Holstein $\times$ Jersey, and Ayrshire $\times$ Jersey crossbreds, respectively. Remarkably, the magnitude of heterosis between the breed combinations is the opposite of our findings, where $\mathrm{DH} \times \mathrm{DR}$ seems to create the most heterosis and $\mathrm{DH} \times \mathrm{DJ}$ the least. However, the results from New Zealand are calculated from simulations based on the conditions for dairy production in New Zealand, which are different from the Danish conditions. Also, as explained earlier, DR has better functional traits compared with DJ and DH, which may explain why heterosis estimates for DR crosses are relatively larger than those for $\mathrm{DH} \times \mathrm{DJ}$ in our study.

In a recent Swedish study, heterosis was estimated based on more than 2.5 million crossbreds of Swedish Red $\times$ Holstein (Jönsson, 2015). Heterosis for survival from first lactation to the end of second lactation was found to be +4.6 and $+4.5 \%$ depending on parent combination, which is slightly larger than our estimate in L2. Heterosis estimates for survival from first lactation to the end of third lactation were estimated to be +13.0 and $+12.3 \%$ depending on parent combination, and these estimates are much larger than our estimates for L3. The Danish and Swedish breeds are supposedly somewhat similar in their genetic makeup because Denmark and Sweden collaborate through the NAV breeding goal and have the opportunity to use the same bulls. It is therefore more likely that the difference in the estimates is attributable to differences in recording the longevity trait. The Swedish study observed whether the cow survived from first to second lactation and first to third lactation. This means that the heterosis estimates are in odds ratios in the Swedish study rather than in productive days as in this study.

The only known Danish crossbreeding experiment on longevity (referred to as the Næsgård experiment) was conducted from 1972 to 1985 on 1,680 cows and 4,471

Table 4. Heterosis effects (measured in percentage and days; SE in parentheses) for 5 longevity (L) traits in crossbreds $^{1}$

\begin{tabular}{|c|c|c|c|c|c|c|}
\hline \multirow[b]{2}{*}{ Trait $^{2}$} & \multicolumn{2}{|c|}{$\mathrm{DH} \times \mathrm{DR}^{3}$} & \multicolumn{2}{|c|}{$\mathrm{DH} \times \mathrm{DJ}$} & \multicolumn{2}{|c|}{$\mathrm{DR} \times \mathrm{DJ}$} \\
\hline & $\%$ & Days & $\%$ & Days & $\%$ & Days \\
\hline L1 & +1.2 & $+4.1(1.3)$ & -0.7 & $-2.5(1.9)$ & -1.2 & $-4.1(3.1)$ \\
\hline $\mathrm{L} 2$ & +3.3 & $\begin{array}{l}+18.1(4.8) \\
\text { - }\end{array}$ & +2.3 & $+12.6(7.0)$ & +3.1 & $+17.0(11.3)$ \\
\hline L3 & +5.7 & $+38.7(8.6)$ & +4.1 & $+28.1(12.8)$ & +7.3 & $+49.4(21.3)$ \\
\hline L4 & +7.7 & $+57.2(12.1)$ & +5.6 & $+42.2(18.5)$ & +6.9 & $+51.6(31.7)$ \\
\hline L5 & +8.5 & $+65.2(15.1)$ & +6.2 & $+48.5(23.6)$ & +7.2 & $+56.2(42.1)$ \\
\hline
\end{tabular}


lactation records (Christensen and Pedersen, 1988). Heterosis on survival after 1 lactation was estimated to be +3.5 for $\mathrm{DH} \times \mathrm{DR}$ and $+8.3 \%$ for Finnish Ayrshire $\times \mathrm{DH}$, but these estimates were not significant. For survival after 2 lactations, heterosis was found to be $+27.4 \%$ for $\mathrm{DR} \times \mathrm{DH}$ and $+21.4 \%$ for Finnish Ayrshire $\times \mathrm{DH}$, and for survival after 3 lactations, heterosis estimates were $+11.1 \%$ for $\mathrm{DR} \times \mathrm{DH}$ and $+15.8 \%$ for Finnish Ayrshire $\times \mathrm{DH}$; however, neither were significant. Compared with our estimates for L1, L2, and L3, the estimates from the Næsgård experiment are relatively large. The reason for these insignificant and extreme results may be the high inbreeding coefficient in DR in the period in which the Næsgård experiment was conducted, which was also one of the reasons for doing the experiment on crossbreeding (Christensen and Pedersen, 1988). Also, the experiment was done almost $30 \mathrm{yr}$ ago, and therefore the genetic difference between the breeds may have been larger at that time. When the Næsgård experiment was conducted, DR consisted of almost 100\% Original Danish Red, whereas DR today constitutes only around $15 \%$ and includes Finnish Ayrshire, among other breeds (SEGES, 2015).

\section{CONCLUSIONS}

The results from this study showed a favorable heterosis for longevity in crossbreds of DJ, DH, and DR and substantiated the idea that crossbreeding can be a beneficial tool for increasing the average lifetime of cows in the Danish dairy cattle population. Despite the low heritability, the additive genetic variation provides a good opportunity for increased genetic progress for longevity in Danish dairy cattle. However, a relatively large residual variation confirmed that longevity is a very complex trait with many factors that are yet to be determined. The effect of breed proportion was insignificant but showed a tendency of better longevity in DJ and DR compared with DH, as expected.

\section{REFERENCES}

Berry, D. P., B. L. Harris, A. M. Winkelman, and W. Montgomerie. 2005. Phenotypic associations between traits other than production and longevity in New Zealand dairy cattle with special emphasis on management traits. Interbull Bull. 33:59-62.

Bijma, P., J. Jensen, and P. Madsen. 1998. Genetic and phenotypic parameters of lifetime and stayability traits in Danish dairy breeds. Acta Agric. Scand. A Anim. Sci. 48:155-164.

Christensen, L. G., and J. Pedersen. 1988. Beretning Fra Statens Husdyrbrugsfors $ø$ g. Krydsning Af Malkekvægracer. Frederiksberg Bogtrykkeri, Frederiksberg, Denmark. de Mello, F., E. L. Kern, and A. Bretas. 2014. Longevity in dairy cattle. J. Adv. Dairy Res. 2:2-3.

Fleischer, P., M. Metzner, M. Beyerbach, M. Hoedemaker, and W. Klee. 2001. The relationship between milk yield and the incidence of some diseases in dairy cows. J. Dairy Sci. 84:2025-2035.

Heins, B. J., L. B. Hansen, and A. De Vries. 2012. Survival, lifetime production, and profitability of Normande $\times$ Holstein, Montbéliarde $\times$ Holstein, and Scandinavian Red $\times$ Holstein crossbreds versus pure Holsteins. J. Dairy Sci. 95:1011-1021.

Heins, B. J., L. B. Hansen, A. J. Seykora, A. R. Hazel, D. G. Johnson, and J. G. Linn. 2011. Short communication: Jersey $\times$ Holstein crossbreds compared with pure Holsteins for production, mastitis, and body measurements during the first 3 lactations. J. Dairy Sci. 94:501-506.

Jairath, L., J. C. M. Dekkers, L. R. Schaeffer, Z. Liu, E. B. Burnside, and B. Kolstad. 1998. Genetic evaluation for herd life in Canada. J. Dairy Sci. 81:550-562.

Jönsson, R. 2015. Estimation of heterosis and performance of crossbred Swedish dairy cows. MS Thesis. Swedish University of Agricultural Sciences, Uppsala, Sweden.

Kargo, M., L. Hjort $\varnothing$, M. Toivonen, J. A. Eriksson, G. P. Aamand, and J. Pedersen. 2014. Economic basis for the Nordic Total Merit Index. J. Dairy Sci. 97:7879-7888.

Lauritsen, U., and P. Flagstad. 2016. Ydelseskontrollens Månedsstatistik alle besætninger. Accessed Nov. 3, 2016. https:// www.landbrugsinfo.dk/Kvaeg/Tal-om-kvaeg/Sider/mndstat12f2. aspx.

Leitch, H. W. 1994. Comparison of international selection indices for dairy cattle breeding. Interbull Bull. 10:1-7.

Lopez-Villalobos, N., D. J. Garrick, C. W. Holmes, H. T. Blair, and R. J. Spelman. 2000. Profitabilities of some mating systems for dairy herds in New Zealand. J. Dairy Sci. 83:144-153.

Madsen, P., and J. Jensen. 2013. A User's Guide to DMU. A Package for Analysing Multivariate Mixed Models. Center for Quantitative Genetics and Genomics, University of Aarhus, Denmark.

Miglior, F., B. L. Muir, and B. J. Van Doormaal. 2005. Selection indices in Holstein cattle of various countries. J. Dairy Sci. 88:12551263. https://doi.org/10.3168/jds.S0022-0302(05)72792-2.

NAV (Nordic Cattle Genetic Evaluation). 2013. NAV routine genetic evaluation of dairy cattle-Data and genetic models. Accessed Nov. 17, 2016. http://www.nordicebv.info/ntm-nordic-total-merit-2/.

Norberg, E., P. Madsen, and J. Pedersen. 2009. A multi-trait genetic analysis of protein yield, udder health, and fertility in first lactation Danish Holstein, Danish Red, and Danish Jersey using an animal model. Acta Agric. Scand. A Anim. Sci. 59:197-203.

Pritchard, T., M. Coffey, R. Mrode, and E. Wall. 2013. Genetic parameters for production, health, fertility and longevity traits in dairy cows. Animal 7:34-46.

Roxström, A., and E. Strandberg. 2002. Genetic analysis of functional, fertility-, mastitis-, and production-determined length of productive life in Swedish dairy cattle. Livest. Prod. Sci. 74:125-135.

SEGES. 2015. Årsstatistik Avl-2014/15. Accessed Apr. 28, 2016. https://www.landbrugsinfo.dk/Kvaeg/Avl/Avlsstatistik/Sider/ aarsstat_2015.pdf.

Sørensen, M. K., E. Norberg, J. Pedersen, and L. G. Christensen. 2008. Invited review: Crossbreeding in dairy cattle: A Danish perspective. J. Dairy Sci. 91:4116-4128.

Vesely, J. A., A. J. McAllister, A. J. Lee, T. R. Batra, C. Y. Lin, G. L. Roy, J. M. Wauthy, and K. A. Winter. 1986. Reproductive performance of crossbred and purebred dairy cows. J. Dairy Sci. 69:518-526.

Weber, A., E. Stamer, W. Junge, and G. Thaller. 2013. Genetic parameters for lameness and claw and leg diseases in dairy cows. J. Dairy Sci. 96:3310-3318. 